Diseases of Vegetables

Bulletin No. 123 of the Ministry of Agriculture and Fisheries. By Lawrence Ogilvie. Second edition. Pp. ii $+74+8$ plates. (London: H.M. Stationery Office, 1944.) 1s. $6 d$. net.

HIS is the second edition of the now well-known bulletin on diseases of vegetables written by Mr. L. Ogilvie, advisory mycologist for the Ministry of Agriculture's western province, with headquarters at Long Ashton Research Station, Bristol.

Among the expert mycologists comprising the Ministry's team of advisers, no one is more fitted than Mr. Ogilvie to write this bulletin. His province includes five counties within the boundaries of which are to be found some of the best vegetable-growing areas, cultivated by some of the most progressive growers of market-garden produce. Long years of experience coupled with his considerable number of investigations into many diseases of vegetables have given Mr. Ogilvie such knowledge of the problems which arise in the successful cultivation of vegetables as to rendor his advice extremely valuable to growers of these crops.

After a brief but lucid introduction explaining the nature of the various kinds of disease, the ones attacking vegetables are described and appropriate measures for preventing or checking them are given. The diseases are referred to by the accepted common name (standardization of which for Great Britain has been attempted in the List of Common British Plant Diseases recently published by the Cambridge University Press); but the full scientific name of the organism causing the disease also appears in brackets after the common name.

Compared with the first edition, there has been some revision and addition in the light of recent discoveries by research workers. There are a score or so of excellent photographs to illustrate some of the important diseases.

Following the main part of the bulletin dealing with vegetable crop diseases, there is a small but useful section giving descriptions of such practices as soil sterilization by steam and chemicals, seed treatment, preparation and use of fungicidal sprays and dusts, disinfecting of glasshouses, etc. There follows a list of the Ministry of Agriculture advisory mycologists with the counties administered by each - this is of great use in indicating where growers can apply for advice on crop troubles.

It is an extromely. well set up publication which every grower of vegetable crops ought to have. The information it contains is written by an expert, and the price, as usual with these bulletins, is within reach of everyone's pocket.

D. E. G.

\section{Radio Technique}

By A. G. Mills. Pp. viii + 170. (London: Chapman and Hall, Ltd., 1944.) 12s. 6d. net.

\section{Radio Receivers and Transmitters}

By S. W. Amos and F. W. Kellaway. Pp. $x+281$. (London : Chapman and Hall, Ltd., 1944.) 21s, net.

THE paucity of new text-books concerned with radio transmission makes the above pair particularly welcome. While we cannot subscribe to the claims of the first author that his text covers among other matters a thorough treatment of transmission and reception necessary for the complete understanding of radio, nevertheless what he has attempted for the young student in a restricted field is well done, and gives a very good idea of the theoretical background necessary in every telecommunications engineer whether specializing in radio transmission or not.

The authors of the second book are slightly more ambitious ; they link up the theoretical work with practice and bring in topics too numerous to mention here. There are many applications of valves which must wait for general disclosure, but this book will certainly impress the student that there are important applications of radio technique, and that to understand them-and in the future to introduce new ones -it is necessary for him to learn much relevant fundamental work. The authors, while not exhausting the subject, have made a careful selection which can be recommended with confidence.

L. E. C. Hughes.

\section{Organic Reagents for Organic Analysis}

By the Staff of the Research Laboratory of Hopkin and Williams, Ltd. Pp. 172. (London: Hopkin and Williams, Ltd., 1944.) $5 s .6 d$.

GSSENTIALLY a summary of a good deal of Ainformation hitherto available only in a dispẹrsed form in recent chemical literature, this book provides a comprehensive list of organic reagents which may be used in identification work for the preparation of crystalline derivatives of various organic types. To illustrate its scope, we may note that under the alcohol type are given eight 'selected reagents' and eleven 'other reagents', the former being as a rule more satisfactory and easier of access than the latter, for details of which the reader is referred to the original literature. Choosing $3: 5$-dinitrobenzoyl chloride as a typical 'selected reagent', we find a description including its structural formula, molecular weight and significant properties, with experimental details for its use in preparing derivatives of alcohols and phenols, together with notes on other applications, a bibliography, and references to tables of meltingpoints given at the end of the volume. To name a less familiar example, xanthydrol is described, on a similar plan, as a reagent for amides, urethanes, sulphonamides and substituted barbituric acids. There is a good index.

The book is evidently an outcome of much firsthand experience, and will be a valuable adjunct to teachers, students, research workers and others concerned with qualitative organic analysis. J. R.

\section{Bentley and Driver's.Textbook of Pharmaceutical} Chemistry

Revised by Dr. John Edmund Driver. Fourth edition. Pp. ix +644. (London, New York and Toronto : Oxford University Press, 1945.) $2 \mathrm{I} s$. net. 7 HIS book is widely used by those who have passed preliminary scientific examinations and are studying for the qualifying examinations in pharmaceutical chemistry. Its suitability for this useful purpose is attested by the appearance of four editions in twenty years. It is divided into three sections dealing with analytical methods, inorganic chemistry and organic chemistry respectively, and is full of facts clearly and simply set forth. A large proportion of these facts is taken from the "Pharmacopoeia", with suitable explanations and amplifications. A few references are given to original papers, but the book is essentially an elementary textbook for a specialized purpose. The new edition has been brought up to date by the inclusion of data from the first six addenda to the "British Pharmacopoeia" of 1932 and revised throughout in the interests of accuracy and clarity. 